\title{
A comparison of referral patterns and characteristics of patients with first episode symptomatic genital HSV-1 and HSV-2 infections in Sheffield
}

\author{
A Nageswaran, R N Shen, J Craig, T T Kyi, C J F Priestley, G R Kinghorn
}

\begin{abstract}
Objective: To ascertain factors associated with HSV-1 and HSV-2 isolates in patients attending a genitourinary medicine clinic with symptomatic first episode genital herpes (FEGH).

Design: Retrospective study.

Subjects: A total of 606 females and 333 males presenting with culture positive FEGH between 1990-94.

Setting: Department of Genitourinary Medicine, Royal Hallamshire Hospital, Sheffield, UK.

Methods: Group comparison of referral patterns, demographic data, prior and concurrent episodes of STD, recent partner change.

Results: HSV-1 infected patients of either sex were more likely to be general practitioner (GP) referred, to be white, and less likely to have had preceding STD episodes. Recent sexual partner change had occurred significantly more often in HSV-2 infected females but there was no similar difference between HSV-1 and HSV-2 infected males.

Conclusion: The relative HSV-1:HSV-2 isolate ratio in FEGH is influenced by the referral patterns. HSV-1 isolates predominate in patients presenting to GPs who refer the patients to GUM clinics for accurate diagnosis, counselling, follow up and screening for other STDs.

(Genitourin Med 1996;72:206-209)
\end{abstract}

Keywords: herpes simplex virus; patient characteristics; serotype; first episode genital herpes

\section{Introduction}

In 1982, Sheffield first reported observing a high proportion of herpes simplex virus type 1 (HSV-1) isolates among women with first episode genital HSV (FEGH) infection. ${ }^{1}$ More recently several other $\mathrm{UK}$ regions have also reported increasing proportions of HSV-1 isolates among women attending genitourinary medicine (GUM) clinics and have noted the possible prognostic significance of this trend. ${ }^{2-4}$ Perceived low risk of transmitting human immunodeficiency virus (HIV) and other sexually transmitted disease (STD) from oral sex and absence of anti HSV-1 antibody in many adolescents and young adults related to improving socio-economic conditions have been postulated as possible reasons for this recent increase in the incidence of HSV-1.

In this study we have compared the demographic characteristics and referral patterns in patients with FEGH infection according to their causative viral type.

\section{Methods and study population}

The study population consisted of all male and female patients who presented with FEGH infection between January 1990 and December 1994. A clinical diagnosis of "first episode" genital HSV infection was made when the patient had multiple painful genital vesicles or ulcers with or without painful/tender inguinal lymphadenopathy and denied a past history of a similar symptomatic disease.
Patients who had a clinical diagnosis suggestive of FEGH which was not confirmed by virus culture were not included in the study.

The patients were grouped according to referral sources; these were (a) "self referred" group which included patients who attended GUM directly for the current complaint, (b) "GP referred" group included patients who attended the general practitioner (GP) initially for the current complaint and were either referred or directed by the GP to attend the GUM, and (c) "other sources" group which included patients who were referred by other health care providers, namely Family Planning Clinics, private clinics and other hospital departments.

Patient records were analysed retrospectively for demographic details, sexual history, parity, partner change within the preceding 3 months, other associated STD and past history of STD. Virus cultures and typing for HSV-1 and HSV-2 isolates with monoclonal antibodies were performed at the Sheffield Regional Public Health Laboratory.

Statistical analysis of data was performed using Epi info, version $6 .{ }^{5}$ Odds ratios and $95 \%$ confidence intervals were calculated for various characteristics of $\mathrm{HSV}-1$ infected individuals as compared with those who were HSV-2 infected.

\section{Results}

A total of 1020 patients satisfied the criteria

Department of
Gentioruinary
Medicine, Directorate
of Communicable
Diseases, Royal
Hallamshire Hospital,
Glossop Road,
Sheffield S10 2JF, UK
A Nageswaran
R N Shen
J Craig
T T Kyi
C J F Priestley
G R Kinghorn
Address correspondence to:
Dr A Nageswaran,
Department of Genitourinary
Medicine, Sexual Health
Centre, St Ann's Hospital,
St Ann' Road, London
N15 3TH, UK.
Accepted for publication
31 January 1996



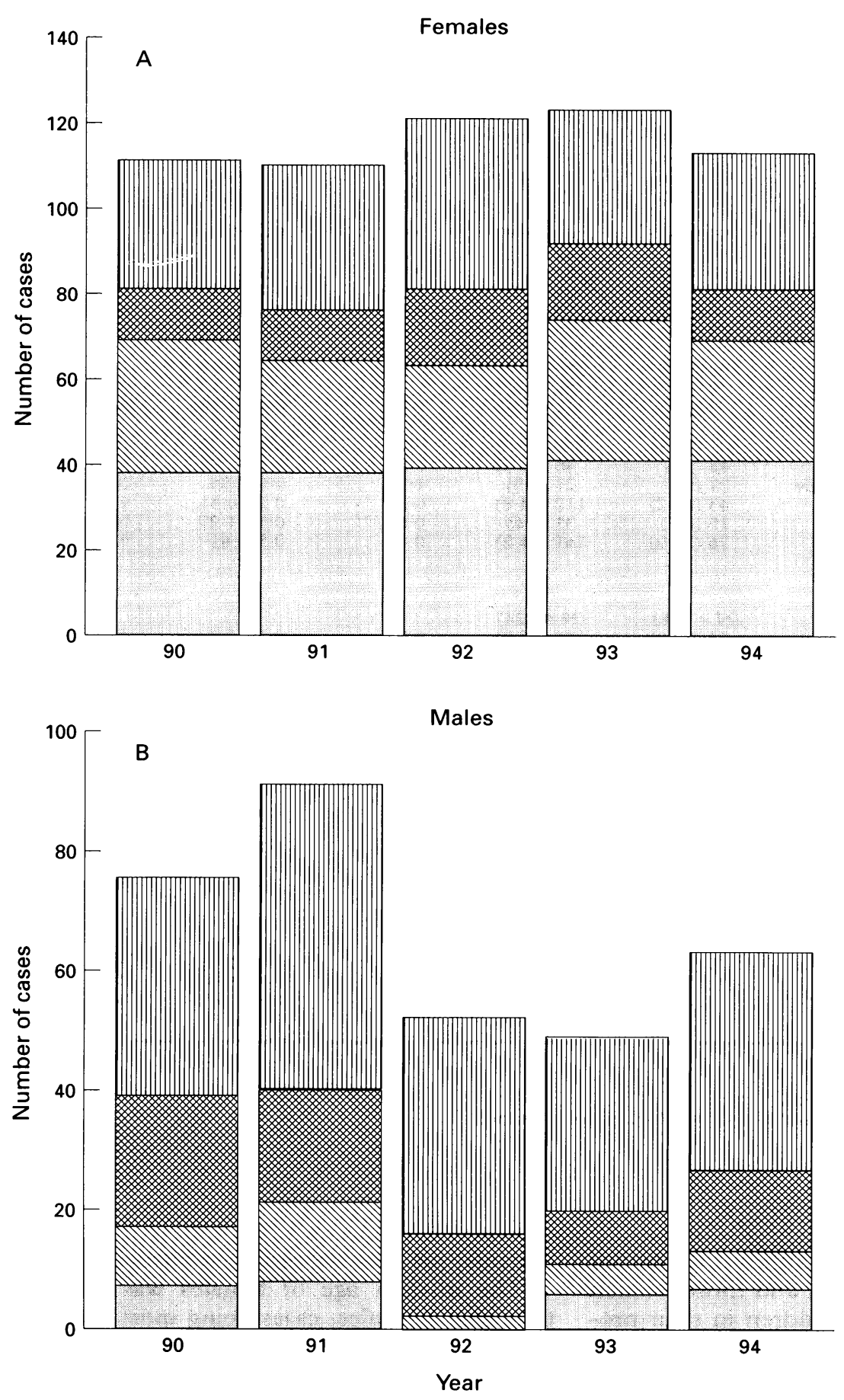

GP HSV-1 Gelf HSV-1

The number of females (a) and males (b) with FEGH seen annually between 1990-94; the subdivisions by virus type isolates and mode of referral are also shown

for a clinical diagnosis of FEGH infection. Of these $81(7 \cdot 9 \%)$ patients, 48 females and 33 males, had no virological confirmation of the diagnosis and hence were excluded from further analysis. The number of females in the study group totalled 606 and males 333, a ratio of $1 \cdot 8: 1$. The figure shows, separately for females (a) and males (b), the number of patients seen annually with FEGH infection and their subdivision by virus type isolates and mode of referral. The mean duration of symptoms prior to attending the clinic was $5 \cdot 5$ days for females and 5.2 days for males (range 1-14 days).

The predominant serotype isolated was
HSV-2 in both sex groups. HSV-1 and HSV-2 were concomitantly isolated from 2 patients ( 1 male \& 1 female) and they were not included for comparative analysis. Among females, the ratio between HSV-1 and HSV-2 isolates was $1: 1 \cdot 1$; this was more pronounced in males who showed a ratio of $1: 2 \cdot 1$.

A comparison of patient characteristics between groups which cultured $\mathrm{HSV}-1$ and HSV-2 serotypes is shown in the table.

Referral method A significantly larger proportion of females with FEGH infection initially presented to their GP compared with males ( $58 \%$ vs $19 \%, p<0.001)$. Of those who had initially visited their GP, $247(73 \%)$ females and $39(61 \%)$ males who referred with a provisional clinical diagnosis of genital herpes. Amongst GP referred patients, HSV-1 was significantly more frequently isolated compared with HSV-2 in either sex. During 1990-1994, females with HSV-1 isolates were almost three times more frequently GP referred than self referred, whereas males with HSV-2 isolates were more than four times more likely to be self-referred as compared with GP referred.

Age The median age for females at presentation was 23 years (mean $25 \cdot 3$, range $12-67$ ) and for males 27 years (mean 29.4, range 15-80). Among teenagers there were proportionately more females than males $(20 \%$ vs $5 \%$ ) whereas amongst those aged 35 years or over a reversed proportion was observed (11\% vs $22 \%$ ).

Ethnic group Whites, blacks and other races including Asians constituted $91 \cdot 3 \%, 6 \cdot 3 \%$ and $2 \cdot 4 \%$ of the study population respectively. White females showed twice as much likelihood of consulting their GP first compared to other races. Among blacks, HSV-1 isolates were significantly uncommon compared with whites ( $<<0.001$ for both sexes). In those females aged less than 25 years, $167(99 \%)$ of 168 with HSV-1 isolates were Caucasian as compared with $169(88 \%)$ of 192 with HSV-2 isolates; the difference between whites and non whites in terms of the virus types isolated was highly significant $\left(\chi^{2}=16.88, \mathrm{p}<0.0001\right)$.

Marital status No significant difference was noted in the serotype isolates among the different marital groups.

History of past STD Previous episodes of STD were significantly more common in patients with HSV-2 isolates of either sex.

Concurrent STD Concurrent STD were found in $50(8 \%)$ females and $31(10 \%)$ males. Of the total concurrent STD in both sexes, 39 $(3 \cdot 8 \%)$ were chlamydial infection, $29(2 \cdot 8 \%)$ genital warts, $11(1 \cdot 1 \%)$ gonorrhoea, 11 $(1 \cdot 1 \%)$ Trichomonas vaginalis infection, and $5(0.5 \%)$ HIV infection. Although accompanying STD was more commonly found in those patients of either sex with HSV-2 isolates, the differences from those with $\mathrm{HSV}-1$ isolates did not achieve statistical significance.

Recent partner change The significant difference observed between females with HSV-1 and HSV-2 isolates in terms of reported recent partner change was not evident amongst males with either HSV type. 
Comparison of patient characteristics between groups which cultured HSV-1 and HSV-2 serotypes on FEGH

\begin{tabular}{|c|c|c|c|c|c|c|}
\hline & & $\begin{array}{l}H S V-1+v e \\
n(\%)\end{array}$ & $\begin{array}{l}H S V-2+v e \\
n(\%)\end{array}$ & $O R$ & $95 \% C I$ & Significance $\ddagger$ \\
\hline $\begin{array}{l}\text { (a) Females } \\
\text { Referral method }\end{array}$ & $\begin{array}{l}\text { Self } \\
\text { GP } \\
\text { Other }\end{array}$ & $\begin{array}{l}(\mathrm{N}=283) \\
72(25 \cdot 4) \\
197(69 \cdot 6) \\
14(5 \cdot 0)\end{array}$ & $\begin{array}{l}(\mathrm{N}=322) \\
167(51 \cdot 9) \\
142(44 \cdot 1) \\
13(4)\end{array}$ & $\begin{array}{l}0 \cdot 32 \\
2 \cdot 90 \\
1 \cdot 24\end{array}$ & $\begin{array}{l}0 \cdot 22-0 \cdot 45 \\
2 \cdot 05-4 \cdot 12 \\
0 \cdot 53-2 \cdot 91\end{array}$ & $\begin{array}{l}t \\
\text { Ns }\end{array}$ \\
\hline Age group & $\begin{array}{l}<20 \\
20-24 \\
25-29 \\
30-34 \\
35-39 \\
>40\end{array}$ & $\begin{aligned} & 55(19 \cdot 4) \\
& 113(40)(19 \cdot 1) \\
& 54(19 \cdot 1) \\
& 29(10 \cdot 2) \\
& 9(3 \cdot 2) \\
& 23(8 \cdot 1)\end{aligned}$ & $\begin{aligned} & 66(20 \cdot 5) \\
& 126(39 \cdot 1) \\
& 67(20 \cdot 8) \\
& 27(8 \cdot 4) \\
& 13(4) \\
& 23(7 \cdot 2)\end{aligned}$ & $\begin{array}{l}0.94 \\
1.03 \\
0.9 \\
1 \cdot 25 \\
0.78 \\
1 \cdot 15\end{array}$ & $\begin{array}{l}0 \cdot 62-1 \cdot 42 \\
0 \cdot 74-1 \cdot 45 \\
0 \cdot 59-1 \cdot 37 \\
0 \cdot 7-2 \cdot 24 \\
0 \cdot 3-1 \cdot 99 \\
0 \cdot 61-2 \cdot 18\end{array}$ & $\begin{array}{l}\text { NS } \\
\text { NS } \\
\text { NS } \\
\text { NS } \\
\text { NS } \\
\text { NS }\end{array}$ \\
\hline Lumi group & $\begin{array}{l}\text { White } \\
\text { Black } \\
\text { Other }\end{array}$ & $\begin{array}{c}280(98 \cdot 9) \\
0 \\
3(1 \cdot 1)\end{array}$ & $\begin{array}{l}289(89 \cdot 8) \\
22(6 \cdot 8) \\
11(3 \cdot 4)\end{array}$ & $\begin{array}{c}10.66 \\
0.3\end{array}$ & $\begin{array}{l}3 \cdot 28-54 \cdot 8 \\
0 \cdot 05-1 \cdot 16\end{array}$ & $\begin{array}{l}t \\
t \\
\text { NS }\end{array}$ \\
\hline $\begin{array}{l}\text { Past H/O STD } \\
\text { Associated STD } \\
\text { Recent partner change }\end{array}$ & $\begin{array}{l}\text { Single } \\
\text { Married } \\
\text { Wid/sep/div }\end{array}$ & $\begin{aligned} 207 & (73 \cdot 1) \\
48 & (17) \\
27 & (9 \cdot 5) \\
43 & (15 \cdot 2) \\
19 & (6 \cdot 7) \\
76 & (26 \cdot 9)\end{aligned}$ & $\begin{array}{r}254(78 \cdot 9) \\
46(14 \cdot 3) \\
21(6 \cdot 5) \\
112(34 \cdot 8) \\
31(9 \cdot 6) \\
149(46 \cdot 2)\end{array}$ & $\begin{array}{l}0.73 \\
1.23 \\
1.51 \\
0.34 \\
0.68 \\
0.43\end{array}$ & $\begin{array}{l}0.49-1.08 \\
0.77-1.95 \\
0.8-2.85 \\
0.22-0.51 \\
0.36-1.27 \\
0.3-0.61\end{array}$ & $\begin{array}{l}\text { NS } \\
\text { NS } \\
\text { NS } \\
t \\
\text { NS } \\
t\end{array}$ \\
\hline $\begin{array}{l}\text { (b) Males } \\
\text { Referral method }\end{array}$ & $\begin{array}{l}\text { Self } \\
\text { GP } \\
\text { Other }\end{array}$ & $\begin{array}{c}\mathrm{N}=108) \\
78(72 \cdot 2) \\
28(25 \cdot 9) \\
2(1 \cdot 9)\end{array}$ & $\begin{array}{c}(\mathrm{N}=224) \\
188(83 \cdot 9) \\
36(16 \cdot 1) \\
0\end{array}$ & $\begin{array}{l}0.5 \\
1 \cdot 83\end{array}$ & $\begin{array}{l}0 \cdot 28-0.9 \\
1.01-3.32\end{array}$ & * \\
\hline Age group & $\begin{array}{l}<20 \\
20-24 \\
25-29 \\
30-34 \\
35-39 \\
>40\end{array}$ & $\begin{array}{c}8(7 \cdot 4) \\
30(27 \cdot 8) \\
33(30 \cdot 6) \\
16(14 \cdot 8) \\
3(2 \cdot 8) \\
18(16 \cdot 6)\end{array}$ & $\begin{array}{l}7(3 \cdot 1) \\
67(29 \cdot 9) \\
69(30 \cdot 8) \\
30(13 \cdot 4) \\
19(8 \cdot 5) \\
32(14 \cdot 3)\end{array}$ & $\begin{array}{l}2 \cdot 48 \\
0.9 \\
0.99 \\
1 \cdot 12 \\
0 \cdot 31 \\
1 \cdot 2\end{array}$ & $\begin{array}{l}0.79-7.85 \\
0.52-1.54 \\
0.58-1.67 \\
0.55-2.27 \\
0.07-1.13 \\
0.61-2.35\end{array}$ & $\begin{array}{l}\text { NS } \\
\text { NS } \\
\text { NS } \\
\text { NS } \\
\text { NS } \\
\text { NS }\end{array}$ \\
\hline Eunnic group & $\begin{array}{l}\text { White } \\
\text { Black } \\
\text { Other }\end{array}$ & $\begin{array}{c}103(95 \cdot 4) \\
3(2 \cdot 8) \\
2(1 \cdot 8)\end{array}$ & $\begin{array}{c}183(81 \cdot 7) \\
35(15 \cdot 6) \\
6(2 \cdot 7)\end{array}$ & $\begin{array}{l}4 \cdot 62 \\
0 \cdot 15 \\
0 \cdot 69\end{array}$ & $\begin{array}{l}1.74-15.4 \\
0.03-0.51 \\
0.07-3.92\end{array}$ & $\begin{array}{l}t \\
\text { NS }\end{array}$ \\
\hline $\begin{array}{l}\text { Past H/O STD } \\
\text { Associated STD } \\
\text { Recent partner change }\end{array}$ & $\begin{array}{l}\text { Single } \\
\text { Married } \\
\text { Wid/sep/div }\end{array}$ & $\begin{array}{c}86(79 \cdot 6) \\
13(12 \cdot 1) \\
9(8 \cdot 3) \\
32(29 \cdot 6) \\
5(4 \cdot 6) \\
52(48 \cdot 1)\end{array}$ & $\begin{array}{c}172(76 \cdot 8) \\
31(13 \cdot 8) \\
21(9 \cdot 4) \\
94(42) \\
26(11 \cdot 4) \\
120(53 \cdot 6)\end{array}$ & $\begin{array}{l}1 \cdot 18 \\
0.85 \\
0.88 \\
0.58 \\
0.37 \\
0.8\end{array}$ & $\begin{array}{l}0 \cdot 65-2 \cdot 16 \\
0 \cdot 4-1 \cdot 78 \\
0 \cdot 36-2 \cdot 11 \\
0 \cdot 35-0.98 \\
0 \cdot 11-1 \cdot 02 \\
0.49-1 \cdot 31\end{array}$ & $\begin{array}{l}\text { NS } \\
\text { NS } \\
\text { NS } \\
\star \\
\text { NS } \\
\text { NS }\end{array}$ \\
\hline
\end{tabular}

$\star=\mathrm{p}<0.05$.

$\dagger=\mathrm{p}<0.001]$

$\neq$ indicates $P$ values derived from $\chi^{2}$ test.

NS = Not significant; OR = Odds ratio; $95 \% \mathrm{CI}=95 \%$ confidence interval.

Parity There was no significant difference between nulligravid women and those women with one or more living children in their proportions with either HSV type.

\section{Discussion}

The annual incidence of symptomatic FEGH among females has remained virtually constant throughout 1990-94 whilst there has been a slight decrease among males. Moreover, the annual HSV-1/HSV-2 isolate ratio in either sex has not shown any marked change. This observation contrasts with published reports from other UK regions which have noted an annually increasing proportion of HSV-1 isolates among females during the 80 s and early 90 s. $^{23}$

Almost twice as many females as males presented with symptomatic FEGH during the 5 year study period. Although this observation is compatible with the increased efficiency of HSV transmission from male to female and more severe clinical manifestations amongst females, the differing modes of referral between the sexes also has a significant impact upon the case sex ratio. Among self-referred patients, the case sex ratio was virtually $1: 1$

The median age of females was younger than that of males, cases being most frequent in the 20-24 year old age group whereas affected males were most frequently in the 25-29 year old age group. Teenagers comprised $20 \%$ of all affected females and only $5 \%$ of all affected males. During the study period we observed that case rates of FEGH (like other STDs) in Sheffield teenagers fell, most markedly amongst males, whereas they increased in 25-34 year olds. This suggests that local educational campaigns promoting safer sex and condom use in young people have been successful. However, the perceived relevance and/or penetration of health educational messages for women in their early $20 \mathrm{~s}$ and men up to the age of 34 appears to be much less. This observation has relevance to future targeting and content of sexual health promotion activities.

The present study clearly reveals that the first port of call for the majority of females with FEGH was their GP. While this may relate to women's perception about GUM services, it is more likely to be because of their own initial suspicion of conditions such as cys- 
titis and vulvo-vaginal candidiasis as the possible cause for the symptoms of FEGH; these were the two commonest conditions provisionally diagnosed at referral by the GPs themselves besides HSV.

This study also clearly highlights the preponderance of HSV-1 isolates amongst GPreferred patients. There was a high degree of accuracy in the provisional diagnoses made by the referring GPs in both sexes. In recent years, GUM services have rapidly expanded in response to the increased emphasis on sexual health. In Sheffield, education of GPs about GUM conditions has also been emphasised, not least the importance in genital herpes of accurate diagnosis, screening for concurrent STDs, patient counselling, and partner management. It is possible that similar developments elsewhere have encouraged GP referrals to GUM and this may be a further reason why there has been a surge in HSV-1 isolates in patients with symptomatic FEGH.

Most males and females had symptoms for several days prior to their presentation at GUM. The median symptom duration of 5 to 6 days was towards the recommended upper limit of the therapeutic window in which antiviral agents can influence the course of the illness. It is clearly important that when patients with genital herpes present to their GP that they be referred the same day to GUM so that their management is not compromised by delay.

The marked difference in predominant HSV serotypes between self- and GP-referred patients is indicative of other differences between those patients with GUM conditions presenting first to GPs as compared with those who self-present at a GUM clinic. The HSV-2 patient group showed a strong correlation with a previous episode of STDs and, in females, recent sexual partner change. Not surprisingly, this group directly accessed the GUM service more commonly. There was also a trend towards an increase in concurrent STDs in HSV-2 infected patients. These findings support the sero-epidemiological findings by Cowan $e t a l^{6}$ and reinforce the association of HSV-2 with sexual lifestyles.

Amongst blacks, symptomatic FEGH due to HSV-1 was very uncommon in either sex. First episode genital HSV-1 infection is almost always the result of a true primary infection with HSV. ${ }^{78}$ Sero-epidemiological surveys, both in the UK and elsewhere, indicate that higher proportions of blacks acquire HSV-1 type specific antibody before adolescence as compared with white or Asian populations. ${ }^{89}$ Adult black populations also tend to have higher HSV-2 seroprevalence rates than agematched Caucasians; subclinical infections may therefore be more common in blacks than whites because of the partial immunity to HSV-2 infection conferred by a prior HSV-1 infection. In contrast, many whites remain fully susceptible to both HSV types when they become sexually active. Improvements in socio-economic conditions are associated with a paradoxical increase in FEGH caused by both HSV-1 and HSV-2; this phenomenon will be exacerbated if there are coincident changes in sexual behaviour patterns in the population.

Acute manifestations of symptomatic FEGH are similar in both HSV-1 and HSV-2. Whilst genital HSV-1 infections are prognostically better than HSV-2 in terms of reduced recurrence rates, reduced asymptomatic viral shedding and reduced transmission rates, ${ }^{7}$ prior HSV-1 infection does not provide full protection from subsequently acquiring an HSV-2 infection which may manifest with less severe clinical features or as an asymptomatic first episode with subsequent asymptomatic viral shedding. ${ }^{810}$ Mothers who acquire HSV-2 close to term and who are seropositive for HSV-1, have a high risk of transmitting the virus to their neonates which equals that of seronegative mothers who get primary infection at term. ${ }^{11}$ It is, therefore, imperative that counselling and follow-up be equally offered for all patients presenting with FEGH irrespective of the causative virus type.

In conclusion this study has shown that a majority of females with symptomatic FEGH in Sheffield initially visit their GP and that there is a marked predominance of HSV-1 isolates in GP referred patients. The increasing awareness by GPs of the importance of referral to GUM clinics for accurate diagnosis and counselling in this condition may account for the rising proportion of $\mathrm{HSV}-1$ isolates in patients with genital herpes attending GUM clinics in the UK.

1 Barton IG, Kinghorn GR, Najem S, Al-Omar LS, Potter $\mathrm{CW}$. Incidence of herpes simplex virus type 1 and 2 isolated in patients with herpes genitalis in Sheffield. $\mathrm{Br} \mathcal{F}$ Venereal Dis 1982;58:44-7.

2 Ross JDC, Smith IW, Elton RA. The epidemiology of herpes simplex Type 1 and 2 infection of the genital tract in Edinburgh 1978-1991. Genitourin Med 1993;69:381-3.

3 Tayal SC, Pattman RS. High prevalence of Herpes simplex virus Type 1 in female anogenital herpes simplex in virus Type 1 in female anogenital herpes simplex in 359-61.

4 Wilson P, Cropper L, Sharp I, Fink C. Apparent increase in the prevalence of herpes simplex virus type 1 genital infections among women. Genitourin Med 1994;70:228.

5 CDC. Epi Info Version 6; $A$ word processing, Database and Statistics System for Epidemiology on Microcomputers. 1994; CDC, Atlanta, Geogia.

6 Cowan FM, Johnson AM, Ashley R, Corey L, Mindel A. Antibody to herpes simplex type 2 as serological marker of sexual lifestyle in populations. BMF 1994;309:1325-9.

7 Corey L. Genital Herpes. In: Holmes KK, Mardh P, Sparling PF et al, eds. Sexually Transmitted Disease. 2nd ed. New York. McGraw-Hill.

8 Nahmias AJ, Lee FK, Beckman-Nahmias S. Sero-epidemiological and sociological patterns of herpes simplex virus infection in the world. Scand F Infect Dis, Suppl 1990; 69:19-36.

9 Ades AE, Peckham CS, Dale GE, Best JM, Jeansson S. Prevalence of antibodies to herpes simplex virus types 1 and 2 in pregnant women, and estimated rates of infection. F Epid Commun Health 1989;43:53-60.

10 Mertz GJ, Benedetti J, Ashley R, Selke SA, Corey L. Risk factors for the sexual transmission of genital herpes. Ann Int Med 1992;116:197-202.

11 Brown ZA, Benedetti J, Ashley $\mathrm{R}$ et al. Neonatal herpes simplex virus infection in relation to asymptomatic maternal infection at the time of labour. $N$ Engl $₹ \mathrm{Med}$ 1991;324:1247-52. 